\begin{tabular}{|c|c|c|}
\hline & $\begin{array}{l}\text { İzmir İktisat Dergisi } \\
\text { İzmir Journal of Economics }\end{array}$ & \\
\hline $\begin{array}{l}\text { ISSN:1308-8173 } \\
\text { Geliş Tarihi: } 09.05 .2019\end{array}$ & $\begin{array}{ll}\text { E-ISSN: } 1308-8505 & \text { YIL: } 2019 \\
\text { Kabul Tarihi: } 10.12 .2019 & \text { Online Yayın: } 31.12 .2019 \\
& \text { ÖZGÜN ARAŞTIRMA / ORIGINAL RESEARCH }\end{array}$ & $\begin{array}{l}\text { Cilt: } 34 \text { Sayı: } 4 \text { Sayfa: } 481-489 \\
\text { Doi: } 10.24988 / \text { ije. } 2019344867\end{array}$ \\
\hline
\end{tabular}

\title{
Türkiye ve Avro Bölgesi Arasındaki İkili Ticaretin Analizi: Marshall-Lerner Koşulu Geçerli mi? *
}

\author{
Mert TOPCU ${ }^{1}$, Salih ÖZDEMIR ${ }^{2}$ \\ Özet
}

\begin{abstract}
Dış ticaretin gelir ve fiyat esnekliklerinin ölçülmesi, özellikle gelişmekte olan ülkelerde ticaret politikasının şekillendirilmesi ve ödemeler dengesinin iyileştirilmesi açısından oldukça önemlidir. Bu noktadan hareketle çalışmanın amacl, önemli ticaret partnerlerimizden oluşan Avro Bölgesi ülkeleri ile yaptığımız ikili ticarette Marshall-Lerner koşulunun analiz edilmesidir. Bu kapsamda, 2004-2017 döneminde Avro Bölgesi ile yaptığımız dış ticaret fonksiyonları panel zaman serilerindeki heterojen eğim katsayılarını tahmin etmek için geliştirilen Genişletilmiş Ortalama Grup (AMG) tahmincisi kullanılarak analiz edilecektir. Elde edilen bulgular, ihracat talebi fiyat esnekliğinin pozitif, ithalat talebi fiyat esnekliğinin ise negatif olduğunu göstermektedir. Ayrıca, Türkiye ve Avro Bölgesi arasındaki ikili ticarette Marshall-Lerner koşulunun geçerli olduğu sonucuna ulaşılmıștır.
\end{abstract}

Anahtar kelimeler: Marshall-Lerner koşulu, İkili ticaret, Türkiye, Avro Bölgesi

Jel Kodu: F14, F31, F40

\section{An Analysis of the Bilateral Trade between Turkey and Eurozone: Does the Marshall-Lerner Condition Hold?}

\begin{abstract}
Estimating the income and price elasticities of foreign trade, especially in emerging economies, has become more of an issue in order for developing appropriate trade policy and improving the balance of payment. From this point of view, the goal of this study is to investigate the validity of the Marshall-Lerner condition given the bilateral trade between Turkey and the Eurozone, which consists of major trading partners of Turkey. To this end, foreign trade functions subject to our trade with the Eurozone countries are analyzed using Augmented Mean Group (AMG) estimator, developed to estimate heterogeneous slope coefficients in panel time series over the period 2004-2017. Findings show that price elasticity of export demand is positive whereas price elasticity of import demand is negative. In addition, findings also indicate that the Marshall-Lerner condition holds given the bilateral trade between Turkey and Eurozone.
\end{abstract}

Keywords: Marshall-Lerner condition, Bilateral trade, Turkey, Euro zone

Jel Codes: F14, F31, F40

\section{GiRiş}

Döviz kurunun önemli bir fiyat değişkeni olması, döviz kurlarının özellikle ödemeler dengesi üzerinde yapacağı etkileri iktisatçılar açısından oldukça cazibeli hale getirmektedir. Uluslararası makro iktisat literatürünün en sık araștırılan konularından biri olan MarshallLerner koşulu, ihracat ile ithalat talebi fiyat esneklikleri mutlak değerleri toplamının birden büyük olması durumunda yurtdışı döviz piyasasının istikrarlı olduğunu ileri sürmektedir. $\mathrm{Bu}$ teoriye göre, ödemeler dengesinde oluşan bir açığı kapatmak için ulusal paranın devalüe edilmesi ya da değer kaybına uğraması ancak Marshall-Lerner koşulunun sağlanması durumunda rasyonel olacaktır. Tersine, ihracat ile ithalat talebi fiyat esneklikleri mutlak değerleri toplamının birden küçük olduğu durumda yurtdışı döviz piyasası istikrarsız olacaktır. Bu toplamın bire eşit olduğu durumda ise döviz kurunda

\footnotetext{
${ }^{*}$ Bu çalışma, Doç. Dr. Mert Topcu danışmanlığında Salih Özdemir tarafından hazırlanan “J Eğrisi Hipotezi: Türkiye ve Avro Bölgesi Arasındaki İkili Ticaret Üzerine Bir Analiz" başlıklı yüksek lisans tezinden türetilmiștir.

${ }^{1}$ Doç Dr., Nevşehir Hacı Bektaş Veli Üniversitesi, İktisadi ve İdari Bilimler Fakültesi, İktisat Bölümü, Merkez / NEVŞEHİR, EMAIL:merttopcu@nevsehir.edu.tr ORCID:0000-0001-8236-9810

2 Yüksek Lisans Öğrencisi., Nevşehir Hacı Bektaş Veli Üniversitesi, Sosyal Bilimler Enstitüsü, Merkez / NEVŞEHİR, EMAIL:sozdemir.salih@gmail.com ORCID: 0000-0002-9583-4379
} 


\section{TOPCU - S. OZDEMIR}

meydana gelecek bir değișiklik ödemeler dengesini etkilemeyecektir (Salvatore, 2013: 516-517).

Uluslararası ticaret, bir ulusun yaşam standartlarını geliştiren, istihdama katkı sağlayan ve tüketicilerin farklı mal ve hizmetlere erișim imkânını artıran önemli bir faktör olarak karşımıza çıkmaktadır. Şekil 1, 1827 yılından günümüze kadar küresel ihracat hacminin nasıl geliştiğini göstermektedir. Özellikle 1970'lerden sonra küresel ihracattaki artışın küresel üretimdeki artıştan daha fazla olması, dış ticaretin artan önemine vurgu yapmaktadır.

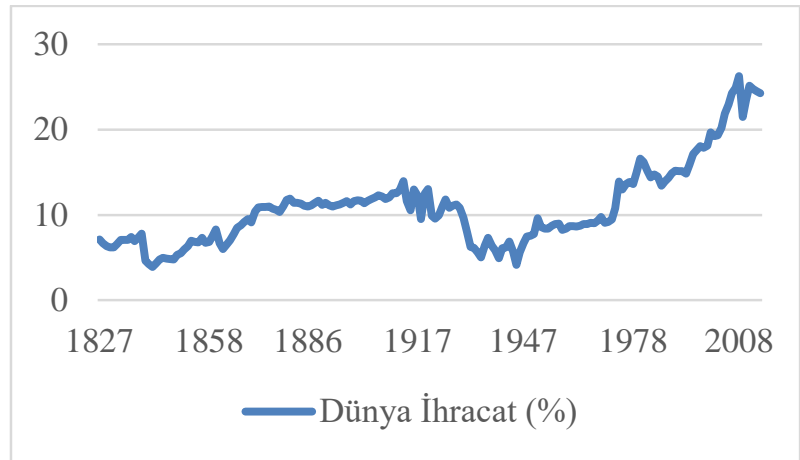

Şekil 1. Global İhracat (\%GSYH)

Kaynak: Frederico ve Tena-Junguito (2017).

Global eğilimle paralel olarak, ülkemizde de dış ticaret hacmi gün geçtikçe artmaktadır. Şekil 2, analize konu olan dönemde (2004-2017) Türkiye'nin dış ticaret hacminin seyrini göstermektedir. Ele alınan dönemde hem ihracat hem de ithalat artan bir seyir izlemekle birlikte, 2004 yllında 51 milyar avro olan ihracat hacmimiz 2017 yılında 140 milyar avroya çıkarken; aynı dönemde ithalat 79 milyar avrodan 207 milyar avroya yükselmiştir. Bu verilere göre 2004-2017 döneminde ihracat yaklaşık 2,7 kat artarken, ithalat 2,6 kat artmıștır.

Şekil 3, Türkiye'nin Avro Bölgesi ülkeleri ile yaptığı dış ticaretin 2004-2017 dönemi itibariyle seyrini göstermektedir. Buna göre, 2004 yılından itibaren Avro bölgesi ülkeleri ile

\footnotetext{
$1 \mathrm{Bu}$ çalışmada ticaret hacmi göz önüne alınırken "Türkiye'nin ticaret ortaklarının" dikkate alındığı belirtilmesine karşın, bu ülkelerin hangileri olduğu
}

yapılan ticaret hacmi hem ihracat hem de ithalat göstergeleri açısından azalan bir trend izlese de, Türkiye'nin toplam dış ticaret hacminin ortalama \%35'i Avro Bölgesi ülkeleri ile gerçekleşmektedir. $\mathrm{Bu}$ önemden yola çlkarak çalışmanın amacı, Türkiye ile Avro Bölgesi ülkeleri arasında ikili ticarette Marshall-Lerner koşulunun geçerli olup olmadığının araştırılmasıdır.

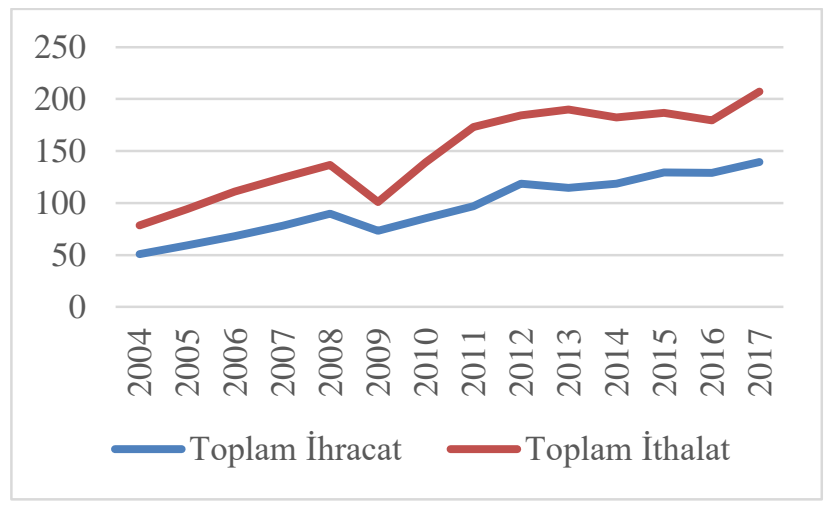

Şekil 2. Türkiye'nin Dış Ticaret Hacmi (milyar Euro)

Kaynak: Türkiye İstatistik Kurumu (TÜİK) Veritabanı.

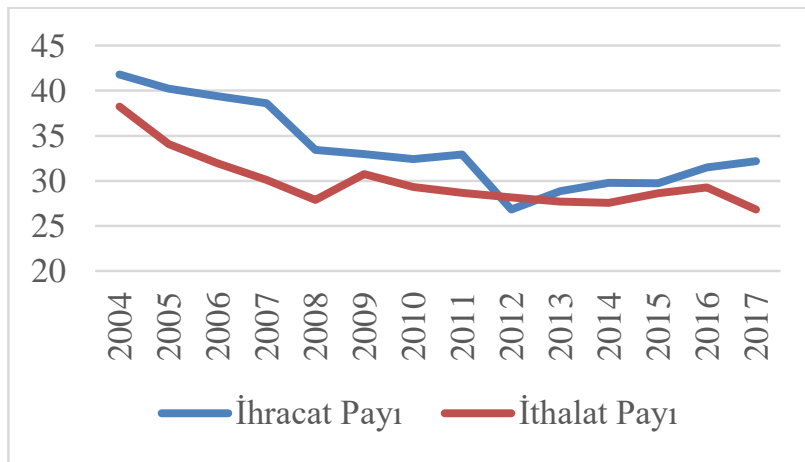

Şekil 3. Avro Bölgesinin Dış Ticaretteki Payı (\%) Kaynak: TÜİK Veritabanı

Türkiye'de Marshall-Lerner koşulunun geçerliliğini araştıran çalışmaların çok bir kısmı ticaret partneri olarak tüm dünyayı analize dahil etmekte ve dolayısıyla ihracat ve ithalat fonksiyonlarını Türkiye'nin toplam dıș ticareti olarak tanımlamaktadır (örneğin, bknz: Göçer ve Elmas, 2013; Bakan ve Akkaya, $2018^{1}$; Vergil ve Erdoğan, 2009; Türkay, 2014; Peker, 2008;

belirtilmediği için toplam dış ticaret fonksiyonu olarak sinıflandırmaya dahil edilmiştir. 
Hepaktan, 2009). Bazı çalışmalar ise tek ülke ve/veya çok ülkeli zaman serisi (örneğin, bknz: Bal ve Demiral, 2012; Halıcıoğlu, 2007) yahut seçilmiş ülkeler için toplam dış ticaret fonksiyonlarını zaman serisi ekonometrisi kullanarak tahmin etmektedir (örneğin, bknz: Şimşek ve Kadılar, 2005; Akbostancl, 2004; Tuncay ve Üstüner, 2017). Mevcut çalışmanın Türkiye üzerine yapılan bu çalışmalardan farkı, panel veri setinin Avro Bölgesi ülkelerine ait gözlemlerden oluşturularak, heterojen panel zaman serisi tahmincisi ile analiz yapılacak olmasıdır.

Çalışmanın kalan kısımlarının planı şu şekildedir: ikinci bölümde ilgili literatür taranacak, üçüncü bölümde uygulamada kullanılacak model ve veri tanitılacak, dördüncü bölümde ampirik yöntem ve bulgular sunulacak, beşinci bölümde elde edilen bulgular tartışılarak politika çıkarımlarına yer verilecek, altıncl bölümde ise genel değerlendirme yapılarak çalışma sonlandırlacaktır.

\section{LİTERATÜR ÖZETI}

Uluslararası literatürde Marshall-Lerner koşulunun geçerli olup olmadığı birçok ülke ve/veya ülke grubu açısından test edilmiştir. Bu çalışmalardan bazıları koşulun geçerli olduğu sonucuna ulaşırken (örneğin, bknz: BahmaniOskooee ve Niroomand, 1998; Boyd, Caporale ve Smith, 2001; Jamilov, 2013; Uslu, 2018; vd.), bazıları ise koşulun geçerli olmadığını tespit etmiştir (örneğin, bknz: Rose, 1991; Loto, 2011; Sek ve Har, 2014; vd.). Çok ülkeli zaman serisi analizi yapan bazı çalışmalar ise koşulun ticaret partnerine göre değişken olduğu sonucuna ulaşmiștır (örneğin, bknz: Mahmud, Ullah ve Yücel, 2004; Hsing, 2010; vd.)

Türkiye ekonomisinde Marshall-Lerner koşulunun geçerliliği üzerine yapılan çalışmaların bir kısmı, koşulun geçerli olduğu sonucuna ulaşmıştır. Göçer ve Elmas (2013), 1989:1-2012:2 döneminde Türkiye'de analize dahil edilen tüm mal grupları için genişletilmiş Marshall-Lerner koşulunun geçerli olduğunu Dinamik En Küçük Kareler (DOLS) tahmincisi ile saptamıştır. Bakan ve Akkaya (2018), 1950-
2000 ylları arasında Türkiye ve ticaret ortakları arasında Marshall-Lerner koşulunun geçerliliğini En Küçük Kareler (OLS) tahmincisi ile analiz etmiş ve ihraç malları için talep elastikiyetini 0,74; ithal mallar için talep elastikiyeti değeri 0,30 bularak MarshallLerner koșulunun geçerli olduğu sonucuna ulaşmıştır. Vergil ve Erdoğan (2009), Gecikmesi Dağıtılmış Otoregresif Sınır testi (ARDL) yaklaşımı ile 1989-2005 dönemine ait çeyreklik verileri kullanarak Türkiye'de Marshall-Lerner koşulunun sağlandığını belirtmiştir. Şimșek ve Kadılar (2005), zaman serisi tahmincilerinden ARDL yaklaşımı ile 1970-2002 dönemine ait yıllık verileri kullanarak Almanya, ABD, Fransa, Hollanda, İngiltere, İspanya, İsviçre ve İtalya gibi majör ticaret partnerlerimizin oluşturduğu bir grup üzerinden Türkiye'de Marshall-Lerner koşulunun geçerli olduğu sonucuna ulaşmıştır. Bal ve Demiral (2012), Türkiye ve Almanya'da 2002:1-2012:9 dönemine ait aylık verileri kullanarak eşbütünleşik denklem üzerinden tahmin ettikleri Marshall-Lerner koşulunun uzun dönemde geçerli olduğunu kanıtlamıştır. Türkay (2014), 1980-2012 dönemine ait ylllı verileri kullanarak Türkiye için MarshallLerner koşulunun eşbütünleşik denklem üzerinden tahmin ettikleri katsayılar çerçevesinde geçerli olduğunu belirtmiştir. Akbostanci (2004), ABD ve Almanya ile Türkiye arasındaki ticaret hacmini 1987-2000 dönemine ait çeyreklik verileri kullanarak uzun dönemde Marshall-Lerner koşulunun geçerli olduğunu eşbütünleşik denklem katsayıları sonucunda raporlamıştır. Eşbütünleşik denklem katsayılarını tahmin eden Halıcıoğlu (2007), 1960-2000 döneminde Türkiye'nin 9 ticaret ortağı (Avusturya, Belçika, Fransa, Almanya, Hollanda, İtalya, İsviçre, Birleşik Krallık ve ABD) ile yaptığı ikili ticarette Marshall-Lerner koşulunun Almanya, Hollanda, İtalya, İsviçre ve ABD için geçerli olduğunu tespit etmiştir.

Türkiye'de Marshall-Lerner koşulunun geçerliliği üzerine yapılan bazı çalışmalar ise koşulun geçerli olmadığı sonucuna ulaşmıştır. Eşbütünleşik denklem katsayıları ve hata düzeltme modeli üzerinden uzun ve kısa 


\section{TOPCU - S. OZDEMIR}

dönemli katsayıları tahmin eden Peker (2008), 1992:1-2006:4 dönemine ait çeyreklik veriler ile döviz kurunda meydana gelen \%1'lik değișmenin ithalat ve ihracat toplamının oluşturduğu ticaret dengesini negatif yönde etkilediğini ve böylece Marshall-Lerner koşulunun geçerli olmadığını tespit etmiştir. 1983-2008 dönemine ait üç aylık verilerle parçalı eşbütünleşme yöntemi uygulayan Hepaktan (2009), Marshall-Lerner koşulunun uzun vadede geçerli olmadığını tespit etmiştir. Tahmin Edilebilir En Küçük Kareler (FGLS) yöntemi ile Tuncay ve Üstüner (2017), 20012015 yılları arasında ekonomik açıdan benzer 9 Avrupa ülkesi için (Türkiye, Rusya, Polonya, Romanya, Bulgaristan, Hırvatistan, Macaristan, Ukrayna, Çekya) Marshall-Lerner koşulunun geçerli olmadığı sonucuna ulaşmıştır. Varyans ayrıştırması ve etki-tepki fonksiyonlarını kullanan Kemeç ve Köseyahyaoğlu (2015), 1997:1-2013:4 dönemine ait aylık veriler ile Marshall-Lerner koşulunun sağlanamadığını raporlamıștır.

\section{MODEL VE VERI}

Çalışmada, 2004-2017 döneminde Türkiye ve Avro bölgesi ülkeleri arasındaki ihracat ve ithalat fonksiyonları tahmin edilecektir. Teoriyle uyumlu olarak, ihracat ve ithalat fonksiyonları, denklem (1) ve denklem (2)'deki gibi oluşturulmuştur.

$X=f\left[Y^{*}, R\right]$ ve $R=E\left(P^{*} / P\right)$

$M=f[Y, R]$ ve $R=E\left(P^{*} / P\right)$

Denklem (1)'deki fonksiyonda yer alan X, Türkiye'nin analizde yer alan ülkelere yaptığ ihracatı; M, aynı ülkelerden yaptığı ithalatı; Y, Türkiye'nin Gayrisafi Yurtiçi Hasılasını (GSYH); $\mathrm{Y}^{*}$, analizde yer alan ülkelerin GSYH'sini; R, reel döviz kurunu; E, nominal döviz kurunu; ve $P$ ve $\mathrm{P}^{*}$ ise sirasıyla Türkiye ve Avro Bölgesi ülkelerinin tüketici fiyat endekslerini temsil etmektedir.

Çalışmada yer alan Avro bölgesi ülkeleri Almanya, Avusturya, Belçika, Estonya, Finlandiya, Fransa, Hollanda, İrlanda, İspanya, İtalya, Letonya, Litvanya, Lüksemburg, Malta,
Portekiz, Slovakya, Slovenya ve Yunanistan'dan oluşmaktadır. GSYH değişkeni cari fiyatlarla Amerikan doları cinsinden ölçülmüş olup Ekonomik Kalkınma ve İşbirliği Örgütü (OECD - Organization for Economic Cooperation and Development) veri tabanından derlenmiștir. Tüketici fiyat endeksleri $(2010=100)$ Dünya Bankası (WB - World Bank) Dünya Gelişim Göstergeleri (WDI - World Development Indicators) veri tabanından temin edilmiştir. Amerikan doları cinsinden ölçülen ihracat ve ithalat değişkenine ait veriler, TÜİK veri tabanı; doğrudan kotasyon ile Euro/TL cinsinden tanımlanan nominal döviz kuru verileri ise Türkiye Cumhuriyet Merkez Bankası (TCMB) Elektronik Vergi Dağıtım Sistemi (EVDS) veri tabanından elde edilmiştir. 2004-2017 dönemine ait yıllık gözlemler derlenerek oluşturulan veri setindeki tüm değişkenler analize doğal logaritmaları alınarak dahil edilmiştir. Buna göre denklem (1) ve (2)'de verilen ihracat ve ithalat fonksiyonları çalışmada tahmin edilecek şekilde panel veri formatında açlacak olursa:

$$
\begin{aligned}
& X_{i, t}=\alpha_{1} Y_{i, t}^{*}+\alpha_{2} R_{i, t}+v_{i}+\varepsilon_{i, t} \\
& M_{i, t}=\beta_{1} Y_{i, t}+\beta_{2} R_{i, t}+v_{i}+\varepsilon_{i, t}
\end{aligned}
$$

Denklem (3) ve (4)'te i indisi ülkeleri $(i=1, \ldots, N)$, $\mathrm{T}$ indisi zaman periyodunu $(\mathrm{t}=1, \ldots, \mathrm{T}), \mathrm{vi}$ ülkespesifik etkileri, $\varepsilon_{i, t}$ ise rassal hata terimini temsil etmektedir. Çalışmada test edilen Marshall-Lerner koşulunun $\left(e_{x}+e_{M}>1\right)$ geçerli olabilmesi için, ihracat talebi fiyat esnekliği $\left(\alpha_{2}\right)$ ile ithalat talebi fiyat esnekliği $\left(\beta_{2}\right)$ mutlak değerleri toplamının birden büyük olması $\left(\alpha_{2}+\beta_{2}>1\right)$ gerekmektedir.

\section{YÖNTEM VE BULGULAR}

Panel veri ekonometri literatüründe meydana gelen son gelişmeler, paneli oluşturan yatay kesitlerin birbirinden etkilenip etkilenmediğini test etmeye imkan tanımaktadır. Paneli oluşturan birimler arasında ortaya çıkması muhtemel bir bağımlılı̆̆ göz ardı etmek, elde edilecek bulguların yanlı ve tutarsız olmasına yol açacaktır. Dolayısıyla çalışmada ampirik çerçevenin ilk ayağı olarak Pesaran (2004) 
tarafından geliștirilen yatay kesit bağımlılı̆ğ (cross-sectional dependence, $\mathrm{CD}$ ) testi uygulanacaktır. Denklem (5), CD testinin matematiksel formatını göstermektedir:

$$
C D=\sqrt{\frac{2 T}{N(N-1)}}\left(\sum_{i=1}^{N-1} \sum_{j=i+1}^{N} \hat{\rho}_{i j}\right)
$$

burada $\mathrm{N}$ ülkeleri, $\mathrm{T}$ zaman periyodunu, $\widehat{\rho_{l j}}$ ise hata terimleri ikili korelasyonunun örneklem tahminini göstermektedir. Tablo 1'in A panelinde raporlanan CD testi sonuçları, "yatay kesit bağımlılığı olmadığı" șeklinde kurulan boș hipotezin tüm değişkenler için reddedildiğini, yani tüm serilerde yatay kesit bağımlılığı sorununun mevcut olduğunu göstermektedir.

Tablo 1: Yatay Kesit Bağımlılığı ve Birim Kök Testi Sonuçları.

\begin{tabular}{|r|r|r|r|}
\hline \multicolumn{3}{|c|}{ PANEL A } & \multicolumn{1}{c|}{ PANEL B } \\
\hline $\begin{array}{c}\text { DEĞIŞKE } \\
\mathrm{N}\end{array}$ & $\begin{array}{c}\text { CD } \\
\text { TESTI }\end{array}$ & $\begin{array}{c}\text { CIPS } \\
\text { (DÜZEY) }\end{array}$ & $\begin{array}{c}\text { CIPS } \\
(1 . F A R K \\
\text { ) }\end{array}$ \\
\hline $\mathrm{X}$ & $26.69^{\mathrm{a}}$ & -2.518 & $-4.181^{\mathrm{a}}$ \\
\hline $\mathrm{M}$ & $28.15^{\mathrm{a}}$ & -2.382 & $-4.044^{\mathrm{a}}$ \\
\hline $\mathrm{Y}$ & $46.28^{\mathrm{a}}$ & 1.700 & 1.700 \\
\hline $\mathrm{Y}^{*}$ & $43.18^{\mathrm{a}}$ & -1.518 & $-2.354^{\mathrm{b}}$ \\
\hline $\mathrm{R}$ & $37.59^{\mathrm{a}}$ & $-2.488^{\mathrm{a}}$ & - \\
\hline
\end{tabular}

CD testi Pesaran (2004) tarafından geliştirilen yatay kesit bağımlılığı testidir.

CIPS testi Pesaran (2007) tarafından geliştirilen birim kök testidir.

CIPS testi sabit terim ve trend içerecek şekilde bir gecikme ile tahmin edilmiştir.

a, b ve c sırasıyla $\% 1, \% 5$ ve $\% 10$ seviyesinde anlamlılığı simgelemektedir.

Granger ve Newbold (1974), regresyon tahmini içeren ekonometrik analizlerde birim kök içeren serilerle tahmin yapılması durumunda sahte regresyon sorununun ortaya çlkabileceğini belirtmektedir. Bu nedenle yatay kesit bağımlılığını takiben ampirik çerçevenin ikinci ayağı olarak birim kök analizine yer verilecektir. Yatay kesit bağımlılığının mevcut olduğu bir sistemde birinci nesil testlerle yapılan birim kök sınaması yanlı sonuçlar üretmektedir. Bu nedenle birim kök sınaması, yatay kesit bağımlılığını göz ardı etmeyen ikinci nesil testlerle yapılmalıdır. $\mathrm{Bu}$ amaçla çalışmada panel veri literatüründe sıklıkla kullanılan ikinci nesil birim kök testlerinden Yatay Kesit Bağımlılığıyla Genişletilmiş Im, Pesaran Shin (CIPS) testinden faydalanılmıştır. Pesaran (2007) tarafından geliştirilen CIPS testi şu şekilde ifade edilmektedir:

$$
\operatorname{CIPS}(N, T)=N^{-1} \sum_{i=1}^{N} t_{i}(N, T)
$$

burada CIPS(N,T) Im, Pesaran ve Shin (2003) tarafından geliştirilen IPS testinin yatay kesitle geliştirilmiş versiyonunu, $t_{i}(N, T)$ ise yatay kesitle geliştirilmiş Dickey Fuller (CADF) istatistiğini göstermektedir. Tablo 1'in B panelinde raporlanan CIPS testi sonuçları, reel döviz kuru haricindeki tüm serilerin birim kök içerdiği sonucuna işaret etmektedir.

Yatay kesit sorunu ve serilerin farklı dereceden durağan olması, regresyon analizinde seçilecek yöntemin önemine işaret etmektedir. Panel veri literatüründe son dönemde popüler hale gelen Ortalama Grup tahmincileri, eşbütünleşme bilgisine ihtiyaç olmaksızın uzun dönemli parametreleri tahmin etmekte kullanılmaktadır (Chudik, Pesaran ve Tosetti, 2011; Kapetanios, Pesaran ve Yamagata, 2011; Pesaran ve Tosetti, 2011; Sadorsky, 2014). Bu bakımdan çalışmada uzun dönemli parametreleri tahmin etmek için Genişletilmiş Ortalama Grup (AMG - Augmented Mean Group) tahmincisinden faydalanılacaktır. Eberhardt ve Bond (2009), Eberhardt ve Teal (2010), ve Bond ve Eberhardt (2013) tarafından geliştirilen AMG tahmincisinin en önemli özelliği, paneli oluşturan tüm yatay kesit katsayılarının homojen olmadığını varsayması (eğim katsayılarının heterojen olmasına imkan tanıması) ve yatay kesit bağımlılığına karşı güçlendirilmiş olmasıdır.

AMG tahmincisi, denklem (3) ve (4)'te verilen ihracat ve ithalat fonksiyonlarını yatay kesit sorununa karşı güçlendirmek amacıyla yatay kesit ortalamalarını içerecek şekilde genişletmektedir.

$X_{i t}=\alpha_{1 i} Y_{i t}^{*}+\alpha_{2 i} R_{i t}+\delta_{1 i} \bar{X}_{t}+\delta_{2 i} \bar{Y}_{t}^{*}+\delta_{3 i} \bar{R}_{t}+$ $\emptyset_{i} \widehat{w}_{t}+v_{i}+\epsilon_{i t}$ 
$M_{i t}=\beta_{1 i} Y_{i t}+\beta_{2 i} R_{i t}+\gamma_{1 i} \bar{M}_{t}+\gamma_{2 i} \bar{Y}_{t}+\gamma_{3 i} \bar{R}_{t}+$ $\emptyset_{i} \widehat{w}_{t}+v_{i}+\epsilon_{i t}$

(7) ve (8) numaralı denklemlerde yatay kesit ortalamaları $\quad\left(\bar{X}_{t}, \bar{M}_{t}, \bar{Y}^{*}{ }_{t}, \bar{Y}_{t}, \bar{R}_{t}\right) \quad$ ortak faktörleri, $\widehat{\omega}_{t}$ standart OLS regresyonundan elde edilen zamana ait kukla katsayılarını temsil etmektedir. AMG tahmincisi, gözlemlenemeyen ortak faktörlerin ortak dinamik bir süreç izlediği iki aşamalı bir tahmin süreci izlemektedir. AMG tahmincisinin matematiksel gösterimi şu şekildedir:

$\widehat{\beta_{A M G}}=N^{-1} \sum_{i=1}^{N} \widehat{\beta_{t}}$

burada $\widehat{\beta_{A M G}}$, yatay kesitler tahmincilerinin ortalamasını ifade etmektedir.

Tablo 2: Regresyon Tahmin Sonuçları

\begin{tabular}{|c|c|c|}
\hline DEĞİSKEN & $\begin{array}{c}\text { DENKLEM } \\
\text { (ihracat) }\end{array}$ & $\begin{array}{c}\text { DENKLEM } \\
4 \text { (ithalat) }\end{array}$ \\
\hline $\mathrm{Y}$ & - & $1.254^{\mathrm{a}}$ \\
\hline $\mathrm{Y}^{*}$ & $1.443^{\mathrm{a}}$ & - \\
\hline $\mathrm{R}$ & $1.531^{\mathrm{a}}$ & $-0.699^{\mathrm{a}}$ \\
\hline Wald & $71.25^{\mathrm{a}}$ & $44.90^{\mathrm{a}}$ \\
\hline CD-testi & 1.67 & -0.59 \\
\hline CIPS-testi & $-3.927^{\mathrm{a}}$ & $-2.850^{\mathrm{b}}$ \\
\hline
\end{tabular}

Parametre tahminleri örneklem ortalamaları olarak hesaplanmıștır.

Tahminler sabit terim içermektedir.

Wald testi tüm eğim katsayılarının 0'a eşit olduğunu test eden bir ki-kare testidir.

CD testi Pesaran (2004) tarafından geliştirilen yatay kesit bağımlılığı testidir.

CIPS testi Pesaran (2007) tarafından geliştirilen birim kök testidir.

CIPS testi sabit terim içerecek şekilde bir gecikme ile tahmin edilmiştir.

a ve b sırasıyla $\% 1$ ve $\% 5$ seviyesinde anlamlılığ simgelemektedir.

Tablo 2, AMG tahmincisinden elde edilen parametre tahminlerini yansitmaktadır. İhracat talebi fonksiyonu için yapılan tahminler sonucunda Avro Bölgesi ülkelerindeki gelir seviyesinin \%1 artması Türkiye'nin bu bölgeye yaptığı ihracatı \%1,44; döviz kurunun \%1 artması ise ihracatımızı \%1,53 arttırmaktadır. İthalat talebi fonksiyonu için yapılan tahminler sonucunda ise Türkiye'de gelir seviyesinin \%1 artması Avro Bölgesi ülkelerinden yaptığımız ithalatı \%1,25 arttırırken; döviz kurunun \%1 artması ithalatımızı \%0,69 azaltmaktadır.

\section{TARTIŞMALAR VE POLİTIKA ÇIKARIMLARI}

Diş ticaret, bir ülkenin ekonomik gelișim sürecinde önemli bir rol oynamaktadır. $\mathrm{Bu}$ bağlamda dış ticaretin gelir ve fiyat esnekliklerinin ölçülmesi, bu değişkenlerin özellikle gelişmekte olan ülkelerde ticaret politikası ve ödemeler dengesi üzerindeki büyük çaplı etkileri sebebiyle önem arz etmektedir (Coşar, 2002). Dolayısıyla çalışmada elde edilen bulguların doğru yorumlanması, politika çıkarımı açısından son derece mühimdir.

Teori ile uyumlu olarak, gelir değișkenin katsayısı hem ihracat hem de ithalat modelinde istatistiki olarak anlaml ve pozitiftir. Bulgu, gelir arttıkça dış ticaret hacmi artar hipotezini desteklemektedir. Her iki modelde de esneklik katsayısının birden büyük olması, dış ticaret talebinin gelir değişimlerine aşırı duyarlı (elastik talep) olduğunu göstermektedir. Ayrıca ihracat talebinin gelir esnekliği, ithalat talebinin gelir esnekliğinden daha büyüktür. Krugman (1989), hızlı büyüyen ekonomilerde ihracat talebi gelir esnekliğinin ithalat talebi gelir esnekliğinden daha yüksek olduğunu ifade etmektedir. Ayrıca bu bulgu Türkiye ekonomisinde Marshall-Lerner geçerliliğini araştıran çalışmalardan Göçer ve Elmas (2013), Yamak ve Korkmaz (2005) ve Türkay (2014) ile uyumlu iken; Vergil ve Erdoğan (2009) ile uyumsuzdur.

İktisat teorisi, ihracat talebi fiyat esnekliğinin pozitif, ithalat talebi fiyat esnekliğinin ise negatif olması gerektiğini söylemektedir. Teori ile uyumlu olarak, ihracat fonksiyonunda fiyat değişkeninin katsayısı pozitif ve istatistiki olarak anlamlı; ithalat fonksiyonunda fiyat değişkeninin katsayısı ise negatif ve istatistiki olarak anlamlıdır. Bu bulgu, döviz kuru arttıkça net ihracat artar (ihracat artar, ithalat azalır) hipotezini desteklemektedir. Ayrıca, ihracat talebinin döviz kuruna duyarlılığının elastik, ithalat talebinin döviz kuruna duyarlılığının ise inelastik olduğu tespit edilmiştir. Bu bulguya 
göre, fiyat değişimleri ithalata kıyasla ihracatı daha fazla etkilemektedir. Üretimde kullanılan ara mallarında yüksek oranda ithalata bağımlı olunması, bu bulguyu açıklar niteliktedir.

Bulgular fonksiyon bazında değerlendirildiğinde de önemli çıkarımlar yapmak mümkündür. İhracat talebi hem gelire hem de fiyata duyarlı iken, ithalat talebi gelire duyarlı ancak döviz kuruna duyarlı değildir. Bu bulgu, Türkiye'de ithalatın milli gelire duyarlılığının döviz kuruna olan duyarlılıklarından daha yüksek çıktığını raporlayan Göçer ve Elmas (2013) ile örtüşmektedir. Buna göre, Türkiye'de ithalat talebini kısıtlamak için döviz kurunu artırmaya yönelik politikalardan ziyade harcanabilir geliri etkileyecek politikaların daha etkili olacağı yorumunda bulunulabilir.

Çalışmadan elde edilen bulgular MarshallLerner koşulu açısından değerlendirildiğinde, Türkiye ve Avro Bölgesi arasındaki ikili ticarette koşulun geçerli olduğu sonucuna ulaşılmıştır. Bulgu, Türkiye'de Avro Bölgesi ile olan ticari faaliyetlerde reel döviz kurunu arttırmaya yönelik uygulanacak politikaların ödemeler dengesini iyileştirmeye yardımcı olabileceği ş̧eklinde yorumlanabilir. Ancak Türkiye'de ihracatın ithal ara mallarına bağımlı yapısı dikkate alındığında, ulusal paranın değerini düşürmeye yönelik uygulanacak politikalar, ara mallarının ithalat fiyatını artırarak maliyet enflasyonuna neden olabilir. Göçer ve Elmas (2013), ara malı ile nihai mal ithalatının ayrıștırılarak bu durumun önüne geçilebileceğini önermektedir. Ayrıca üretim etkisi de göz önüne alındığında, döviz kuru politikaları ithalat vergi reformları ile desteklenerek, üretim temelli ithalatı teşvik eden ancak tüketim temelli ithalatı kısıtlayan politikalar eş zamanlı olarak uygulanabilir.

\section{SONUÇ}

Bu çalışma, Türkiye'nin ihracat ve ithalat talebi fonksiyonlarını Avro Bölgesi ülkeleri ile yaptı̆̆ ikili ticaret üzerinden tahmin ederek, MarshallLerner koşulunun geçerliliğini araştırmayı amaçlamaktadır. Kurulan fonksiyonlar, panel zaman serilerindeki heterojen eğim katsayılarını hesaplamak için geliştirilen Genişletilmiş Ortalama Grup (AMG) tahmincisi ile tahmin edilmiştir. Elde edilen bulgular, 2004-2017 döneminde ihracat talebinin gelir ve fiyat esnekliğinin birden büyük; ithalatın ise gelir esnekliğinin birden büyük, fiyat esnekliğinin ise birden küçük olduğunu göstermektedir. Ayrıca, mutlak değer olarak ihracat ve ithalat talebinin fiyat esnekliği toplamının birden büyük olması, analiz periyodunda Türkiye'de Marshall-Lerner koşulunun geçerli olduğuna işaret etmektedir.

Bu çalışma, geleneksel bir teoriyi Türkiye'nin önemli ticaret partnerlerinden oluşan panel bir grupta, güncel bir zaman periyodunda ve daha evvel kullanılmamış bir tahmin yöntemiyle ele almaktadır. Bu konuda çalışma yapacak araştırmacılar, dış ticareti mal grupları bağlamında ele alarak Marshall-Lerner koşulunun geçerliliğini toplamın yanlılı̆̆ (aggregation bias) sorununu dikkate alarak inceleyebilirler.

\section{REFERANSLAR}

Akbostancl, E. (2004). Dynamics of the Trade Balance: The Turkish J-Curve. Emerging Markets Finance and Trade, 40(5), 57-73.

Bahmani-Oskooee, M., Niroomand, F. (1998). Long-run Price Elasticities and the MarshallLerner Condition Revisited. Economics Letters, 61(1), 101-109.
Bakan, S., Akkaya, O. (2018). Marshall-Lerner Koşulunun Türkiye Ekonomisinde İncelemesi: 1950-2000 Dönemi. Anemon Muş Alparslan Üniversitesi Sosyal Bilimler Dergisi, 6 (ICEESS'18), 325-331.

Bal H., Demiral, M. (2012). Reel Döviz Kuru ve Ticaret Dengesi: Türkiye'nin Almanya ile Ticareti Örneği (2002.01-2012.09). Çukurova 


\section{TOPCU - S. OZDEMIR}

Üniversitesi İktisadi ve İdari Bilimler Fakültesi Dergisi, 16(2), 45-64.

Bond, S., Eberhardt, M. (2013). Accounting for Unobserved Heterogeneity in Panel Time Series Models. Nuffield Collage, University of Oxford, Mimeo.

Boyd, D., Caporale, G. M., Smith, R. (2001). Real Exchange Rate Effects on the Balance of Trade: Cointegration and the Marshall-Lerner Condition. International Journal of Finance \& Economics, 6(3), 187-200.

Chudik, A., Pesaran, M. H., Tosetti, E. (2011). Weak and Strong Cross-section Dependence and Estimation of Large Panels. The Econometrics Journal. 14, C45-C90.

Coşar, E. E. (2002), .Price and Income Elasticities of Turkish Export Demand: A Panel Data Application. Central Bank Review, 2(2), 19-53.

Eberhardt, M., Bond, S. (2009). Cross-section Dependence in Nonstationary Panel Models: A Novel Estimator. Munich Personal RePEc Archive Working Paper No. 17870, Germany.

Eberhardt, M., Teal, F. (2010). Productivity Analysis in Global Manufacturing Production. (Economic Series Working Paper 515). University of Oxford, Department of Economics.

Federico, G., Tena-Junguito, A. (2017). A Tale of Two Globalizations: Gains From Trade and Openness 1800-2010. Review of World Economics, 153(3), 601-626.

Göçer, İ., Elmas, B. (2013). Genişletilmiş Marshall-Lerner Koşulu Çerçevesinde Reel Döviz Kuru Değişimlerinin Türkiye'nin Dış Ticaret Performansına Etkileri: Çoklu Yapısal Kırılmalı Zaman Serisi Analizi. BDDK Bankacılık ve Finansal Piyasalar, 7(1), 137-157.

Granger, C. W.J., Newbold, P. (1974). Spurious Rregressions in Econometrics. Journal of Econometrics, 2, 111-120.

Halıcıoğlu, F. (2007). The J-curve Dynamics of Turkish Bilateral Trade: A Cointegration Approach. Journal of Economic Studies, 34(2), 103-119.
Hepaktan, C. E. (2009). Türkiye'nin MarshallLerner Koşuluna İlişkin Parçalı Eşbütünleşme Analizi. Yönetim ve Ekonomi: Celal Bayar Üniversitesi İktisadi ve İdari Bilimler Fakültesi Dergisi, 16(1), 39-55.

Hsing, Y. (2010) Test of the Marshall-Lerner Condition for Eight Selected Asian Countries and Policy Implications. Global Economic Review, 39(1), 91-98.

http://tuik.gov.tr/PreTablo.do?alt_id=1046, (10.04.2019).

https://data.oecd.org/gdp/gross-domesticproduct-gdp.htm, (11.04.2019).

http://datatopics.worldbank.org/worlddevelopment-indicators/, (11.04.2019).

https://evds2.tcmb.gov.tr/, (09.04.2019).

Im, K. S., Pesaran, M. H., Shin, Y. (2003). Testing for Unit Roots in Heterogeneous Panels. Journal of Econometrics, 115(1), 53-74.

Jamilov, R. (2013). J-Curve Dynamics and the Marshall-Lerner Condition: Evidence from Azerbaijan. Transition Studies Review, 19(3), 313-323.

Kapetanios, G., Pesaran, M. H., Yamagata, T. (2011). Panels with Non-stationary Multifactor Error Structures. Journal of Econometrics, 160(2), 326-348.

Kemeç, A., Köseyahyaoğlu, L. (2015). J Eğrisi Analizi ve Türkiye Üzerine Bir Uygulama. Uluslararası İktisadi ve İdari Bilimler Dergisi, 1(2), 1-29.

Krugman, P. (1989). Differences in Income Elasticities and Trends in Real Exchange Rates. European Economic Review, 33(5), 1031-1046.

Loto, M. A. (2011). Does Devaluation Improve the Trade Balance of Nigeria? (A test of the Marshall-Lerner Condition). Journal of Economics and International Finance, 3(11), 624-633.

Mahmud, S. F., Ullah, A., Yücel, E. M. (2004). Testing Marshall-Lerner Condition: A Nonparametric Approach. Applied Economics Letters, 11(4), 231-236. 
Newbold, P., Granger, C. W. (1974). Experience with Forecasting Univariate Time Series and the Combination of Forecasts. Journal of the Royal Statistical Society: Series A (General), 137(2), 131-146.

Peker, 0. (2008). Reel Döviz Kurunun Ticaret Dengesi Üzerindeki Etkileri: Türkiye Örneği. Atatürk Üniversitesi İktisadi ve İdari Bilimler Dergisi, 22(2), 33-43.

Pesaran, M. H. (2004). General Diagnostic Tests for Cross Section Dependence in Panels. Cambridge Working Papers in Economics No. 0435, University of Cambridge, June 2004.

Pesaran, M. H. (2007). A Simple Panel Unit Root Test in the Presence of Cross-section Dependence. Journal of Applied Econometrics, 22(2), 265-312.

Pesaran, M. H., Tosetti, E. (2011). Large Panels with Common Factors and Spatial Correlation. Journal of Econometrics, 161(2), 182-202.

Rose, A. K. (1991). The Role of Exchange Rates in a Popular Model of International Trade: Does the 'Marshall-Lerner' Condition Hold?. Journal of International Economics, 30(3-4), 301-316.

Sadorsky, P. (2014). The Effect of Urbanization on $\mathrm{CO} 2$ Emissions in Emerging Economies. Energy Economics, 41, 147-153.

Salvatore, D. (2013). International Economics (Eleventh Editition). Wiley \& Sons, United States.

Sek, S. K., Har, W. M. (2014). Testing for Marshall-Lerner Condition: Bilateral Trades between Malaysia and Trading Partners. Journal of Advanced Management Science, 2(1), 23-28.

Şimșek, M., Kadılar, C. (2005). Türkiye'nin İhracat Talebi Fonksiyonunun Sinır Testi Yöntemi ile Eşbütünleşme Analizi. Doğuş Üniversitesi Dergisi, 6(1), 144-152.

Türkay, H. (2014). The Validity of MarshallLerner Condition in Turkey: A Cointegration Approach. Theoretical \& Applied Economics, 10(599), 21-32.
Uslu, H. (2018). Marshall-Lerner Koşulu ve J Eğrisi Hipotezinin Geçerliliği: Farklı Gelir Gurubu Ülkeleri için Karşılaştırmalı Bir Analiz. International Journal of Academic Value Studies, 4(20), 550-561.

Tuncay, Ö., Üstüner, T. S. (2017). Gelişmekte Olan Ülkelerde Dıș Ticaret Dengesini Belirleyen Faktörlerin Marshall-Lerner Koşulu Çerçevesinde Analizi. Journal of Social and Humanities Sciences Research, 4(12), 956-964.

Vergil, H., Erdoğan, S. (2009). Döviz KuruTicaret Dengesi İlişkisi: Türkiye Örneği. Zonguldak Karaelmas University Journal of Social Sciences, 5(9), 35-57.

Yamak, R., Korkmaz, A. (2005). Reel Döviz Kuru ve Diş Ticaret Dengesi İlişkisi. Ekonometri ve İstatistik e-Dergisi, 2, 16-38. 